\title{
Antiretroviral Service to HIV Patients of low CD4 Count in Seti Zonal Hospital
}

\author{
Paudel BN, ${ }^{1}$ Chaudhary SR, ${ }^{2}$ Sharma S, ${ }^{3}$ Dhungana GP, ${ }^{4}$ Paudel P5 \\ 'Department of Medicine, Seti Zonal Hospital, Dhangadi, Kailali, 2Department of Gastrointerology, Bir Hospital, NAMS, ${ }^{3}$ Department of \\ Medicine and Chief of HIV unit, Tribhuvan University, Teaching Hospital, Kathmandu, ${ }^{4}$ Department of Microbiology, Siddhanath science \\ campus, Mahendranagar, Kanchanpur, ${ }^{5}$ Paropakar Hospital, Thapathali, Kathmandu
}

\begin{abstract}
Introduction: Due to unavailability of vaccine against HIV/AIDS, there are no ways other than relying on ART. We select group of late stage HIV/AIDS with $C D 4<50$ so that opportunistic infections and outcome of patients in this late stage of severe immunosuppression after initiation of ART can be known
\end{abstract}

Methods: A cross sectional study was carried out in 53 HIV patients with CD4 count < 50 cells/cu mm blood undergoing ART in Seti Zonal Hospital Dhangadi between December 2006 and May 2008 with objectives to explore the treatment outcome in this late stage of immunosuppression. Only those patients with CD4 count $<50$ were consecutively selected and recommended for various laboratory test on the basis of which ART regimen were prescribed. Results: Among 53 patients, 42 (79.2\%) were males and $11(20.8 \%)$ were females, with predominant age group of 30-40 years $(49.1 \%)$. Fever $(71.7 \%)$, diarrhea $(56.6 \%)$, pneumonia $(52.8 \%)$, weight loss $(52.8 \%)$ and oral thrush $(33.9 \%)$ were found to be the major clinical presentation/Opportunistic infections. 19 (35.8\%) patients showed normal activity throughout the treatment period with increase in CD4 count, 10 (19\%) were recovered and transferred out. Only 1 (1.8\%) showed decrease in CD4 count even after taking ART. Significant relationship was established between the intake of ART and increase in CD4 level (pair $\mathrm{t}=7.88$, $\mathrm{p}<0.05)$.

Conclusions: ART service was found to be efficient enough to increase the CD4 count significantly after 6 months of therapy but the prevalence of OIs/clinical manifestations were sufficiently higher in this group of patients with low CD4 count.

Key words: antiretroviral therapy, cell count, fever, opportunistic infections

\section{INTRODUCTION}

Due to unavailability of vaccine against HIV/AIDS, there are no ways other than relying on antiretroviral therapy (ART) for which is directed against the replication of HIV so that there will be reduction of HIV related mortality and morbidity, improvement of quality of life, restoration and /or preservation of immunological function and maximal and durable suppression of viral replication. $^{1}$
CD4 cells, which decreases with the severity of HIV progression, are one of the widely used laboratory markers used to guide clinical and therapeutic management of AIDS cases. ${ }^{2,3}$ It has been estimated that about $80 \%$ patients with CD4 count below 200 develop AIDS with in 4 years and $40 \%-50 \%$ of the patients with CD4 count $200-400$ develop AIDS in 4 years. $^{4}$
Correspondence:

Dr. Bidhan Nidhi Paudel

Department of medicine

Seti Zonal hospital, Dhangadi, Kailali

Email: bidhan_dr2005@yahoo.com

Phone: 9741042550 
Paudel et al. Antiretroviral Service to HIV patients of low CD4 count in Seti Zonal Hospital

In context to Nepal, number of People living with HIV is over 75,000, and as of 12 April 2008, 11,234 HIV cases are reported by official data of National centre for AIDS and STD control (NCASC). ${ }^{5}$ We select group of late stage HIV/AIDS with CD $4<50$ so that opportunistic infections and outcome of patients in this late stage of severe immunosuppression after initiation of ART can be known.

\section{METHODS}

A cross-sectional study was carried out in 53 HIV patients with CD 4 less than 50 cells per cu mm blood undergoing ART in Seti Zonal Hospital, Dhangadi between December 2006 and May 2008. Although this ART centre provide ART to all the patients with CD4 count about or below 200, we purposively selected only those patients with CD4 count $<50$ consicutively (inclusion criterion). CD 4 counts were done for each patient in the baseline and then in the regular interval of six months thereafter. Before the initiation of ART, several factors were considered, among which WHO's clinical staging of HIV and CD4 count are the most important parameters. A rigorous selection procedure was done as per NCASC guideline i.e. the eligibility for ART was determined by criteria that combine an assessment of the clinical and social indication of the patients, as well as their anticipated ability to adhere to ART. Only HIV infected persons who attended HIV care unit of Seti Zonal Hospital were considered for ART. Adherence to cotrimoxazole prophylaxis and TB treatment were used to assess ability to adhere to ART. After the patients have been counseled for ART, their social and support structure were assessed. Person's family environment and disclosure to at least one person (who will act as a treatment assistant) was verified. Other factors like alcohol abuse and geographical instability were also considered. Once selected for ART, the person was reassessed by physician. Appropriate laboratory tests such as Liver Function test (LFT), kidney function tests; acid fast bacilli (AFB) of sputum (for diagnosis of tuberculosis), urine/stool analysis, total count/Differential count and hemoglobin were performed in regular interval to assess the subsequent response to ART and potential adverse effects. Patients were referred to do CD4 count at every six months and monitoring of the progress was done. Follow up was maintained as: every two weeks in the first month, monthly up to the third month after start of ART, then once in every three months and as necessary of patients.

The information generated through counseling, laboratory findings, and regular health check up of clinician was entered into SPSS 11.5 and analyzed to draw the required inference.

\section{RESULTS}

Among 53 HIV patients with CD4 count less than 50 per cu $\mathrm{mm}$ blood, $42(79.2 \%)$ were males and 11 $(20.3 \%)$ were females. Majority of them were in the age group $30-40$ years $(49.1 \%)$ (Table 1$)$.

Table 1. Distribution of patients by Age and Gender

\begin{tabular}{lccc}
\hline Age group & $\begin{array}{c}\text { Male } \\
\text { Number } \\
(\%)\end{array}$ & $\begin{array}{c}\text { Female } \\
\text { Number } \\
(\%)\end{array}$ & $\begin{array}{c}\text { Total } \\
\text { Number } \\
(\%)\end{array}$ \\
\hline $1-10$ & $1(2.4)$ & $1(9.1)$ & $2(3.8)$ \\
$10-20$ & $2(4.8)$ & $0(0)$ & $2(3.8)$ \\
$20-30$ & $11(26.2)$ & $1(9.1)$ & $12(22.6)$ \\
$30-40$ & $21(50.0)$ & $5(45.5)$ & $26(49.1)$ \\
$40-50$ & $7(16.7)$ & $4(36.4)$ & $11(20.8)$ \\
Total & $42(100)$ & $11(100.0)$ & $53(100.0)$ \\
\hline
\end{tabular}

About $35.8 \%$ of the patients had CD4 count between 40 and 50 cells per cu mm blood. Four patients (7.5\%) had CD4 count below 10 and as high as $45.3 \%$ (24/53) patients had CD4 count less than 30 (Table 2).

Table 2. Distribution of HIV patients by CD4 count

\begin{tabular}{cccc}
\hline $\begin{array}{c}\text { CD4 range } \\
\text { (/cu mm } \\
\text { blood) }\end{array}$ & $\begin{array}{c}\text { Male } \\
\text { Number } \\
(\%)\end{array}$ & $\begin{array}{c}\text { Female } \\
\text { Number } \\
(\%)\end{array}$ & $\begin{array}{c}\text { Total } \\
\text { Number } \\
(\%)\end{array}$ \\
\hline $1-10$ & $4(9.5)$ & $0(0)$ & $4(7.5)$ \\
$10-20$ & $3(7.1)$ & $2(18.2)$ & $5(9.4)$ \\
$20-30$ & $13(31.0)$ & $2(18.2)$ & $15(28.3)$ \\
$30-40$ & $8(19.0)$ & $2(18.2)$ & $10(18.9)$ \\
$40-50$ & $14(33.3)$ & $5(45.5)$ & $19(35.8)$ \\
Total & $42(100.0)$ & $11(100.0)$ & $53(100.0)$ \\
\hline
\end{tabular}

As high as $71.7 \%$ patients presented fever as the major clinical presentation of HIV/AIDS due to different opportunistic infections, followed by diarrhea (56.6\%) and weight loss ( $52.8 \%$ ). Pneumonia, oral thrush and pulmonary tuberculosis were found to be the major opportunistic infections (Table 3).

Among 53 patients, 19 showed normal activity throughout the study period with increase in CD4 cells (They belong to the group with CD4 count improvement), while one patients showed decrease in CD 4 cells. Of the remaining cases, 10 were improved enough to be transferred out and other 10 were expired. As only one patient had shown the decrease in CD4 count after taking ART, we could not compare this case with other patients with increase in CD4 count. Due to transferred out/loss to follow up, no comparison could be done between the patients with increase in CD4 count and 
Paudel et al. Antiretroviral Service to HIV patients of low CD4 count in Seti Zonal Hospital

patients who had not done the CD4 count. As the CD4 count requires Rs. 100, many people hesitate to pay this amount. Poverty, remoteness and illiteracy were found to be the major factors associated with problems of follow up. Beside these many patients were transferred to their nearby ART sites (Doti, Accham, Banke, Surkhet, Dang, Mumbai-India etc) and may find difficult to follow up in doing CD4 count in this site. Despite this fact good adherence $(>95 \%)$ has been noted (Table 4).

Table 3. Different types of Clinical presentation / Opportunistic infections in HIV patients

\begin{tabular}{lc}
\hline \multicolumn{1}{c}{$\begin{array}{c}\text { Clinical feature/opportunistic } \\
\text { infections }\end{array}$} & Number (\%) \\
\hline Fever & $38(71.7)$ \\
Diarrhea & $30(56.6)$ \\
Weight loss & $28(52.8)$ \\
Pneumonia & $28(52.8)$ \\
Oral thrush & $18(33.9)$ \\
Esophageal candidacies & $13(24.5)$ \\
Skin rash /itching & $5(9.4)$ \\
Pulmonary tuberculosis & $5(9.4)$ \\
Herpes zoster & $4(7.5)$ \\
Lymphadenopathy & $3(5.6)$ \\
\hline
\end{tabular}

Table 4. Performance of the patients undertaking ART

\begin{tabular}{ll}
\hline Features & Number \\
\hline $\begin{array}{l}\text { Normal activity with increase in CD4 } \\
\text { count after start of ART }\end{array}$ & 19 \\
Decrease in CD4 count & 1 \\
CD4 not done & 13 \\
Recovered and transferred out & 10 \\
Expired & 10 \\
Total & 53 \\
\hline
\end{tabular}

Among 53 patients, only 20 patients had done CD4 count after 6 month of the start of ART. The other patients had not done the CD4 count due to several reasons such as loss to follow up (LFU), Death, Transferred out, remoteness etc. Furthermore, the CD4 count requires Rs 100, many people hesitate to pay this amount.Among the patients who had done CD4 count after six month of the start of ART, Significant relationship was established between the ART and the increase in CD4 count (pair $t=7.88, p<0.05$ ) (Table 5).
Table 5. CD4 status of the patients before and after ART

\begin{tabular}{cccc}
\hline $\begin{array}{c}\text { CD4 } \\
\text { count at } \\
\text { the Start } \\
\text { of ART } \\
\text { (Initial) }\end{array}$ & $\begin{array}{c}\text { CD4 } \\
\text { count } \\
\text { after } 6 \\
\text { month } \\
\text { of ART } \\
\text { (Final) }\end{array}$ & $\begin{array}{c}\text { Pair } \\
\text { difference } \\
\text { in mean } \\
\text { CD4 count } \\
\text { (final } \\
\text { - initial ) }\end{array}$ & $\begin{array}{c}\text { Pair T test } \\
\text { value }\end{array}$ \\
\hline 50.00 & 260.00 & & \\
25.00 & 178.00 & & \\
45.00 & 203.00 & & \\
49.00 & 295.00 & & \\
16.00 & 300.00 & & \\
2.00 & 3.00 & & \\
5.00 & 96.00 & & \\
50.00 & 303.00 & & \\
16.00 & 194.00 & & \\
26.00 & 139.00 & 173.7 & \\
45.00 & 32.00 & & \\
37.00 & 208.00 & & \\
14.00 & 121.00 & & \\
21.00 & 315.00 & & \\
28.00 & 380.00 & & \\
42.00 & 360.00 & & \\
41.00 & 112.00 & & \\
28.00 & 163.00 & & \\
35.00 & 215.00 & & \\
42.00 & 214.00 & & \\
\hline & & & \\
\hline
\end{tabular}

In many cases quality of life had been improved after taking ART for six months as revealed by weight gain and their ability to do routine work actively. Regarding the side effects of ART, cases taking the ART regimen containing Zidovudine (AZT) few patients developed severe anemia and thrombocytopenia. Patients had been recovered by changing the ART regimen (Stavudine (d4T30) instead of AZT) and several units of blood transfusion. Wasting and lipodystrophy had been developed in some patients taking d4T 30. Some patients taking Neverapine (NVP) developed Hepatitis (jaundice and increased liver function test) and severe form of skin reaction (Steven Johnson syndrome). Most of the cases developed GI disturbances (loss of appetite, pain and distension of abdomen) with AZT.

\section{DISCUSSION}

Despite the fact that housewives (mainly widow and children) comprise the major proportion of HIV community in far western region of Nepal, our study comprised as high as $79.2 \%$ males. ${ }^{6}$ This is because of the inclusion of only those HIV patients with CD4 count $<50$ cells $/ \mathrm{cu} \mathrm{mm}$ blood. This data indicate the 
Paudel et al. Antiretroviral Service to HIV patients of low CD4 count in Seti Zonal Hospital

HIV transmission pattern existing in far western Nepal. Most of the males (Mainly Indian returnee) visit Seti Zonal Hospital complaining several persistent clinical features on the basis of which clinicians suspect the HIV infection in them and recommend for blood test which usually gives positive results. Later low CD4 results are usually obtained even at their first count indicating that they are in the late stage of HIV infection. This fact is further supported by the table 3 which shows $71.7 \%$ fever and $52.8 \%$ pneumonia. Despite this bitter facts table 5 clearly shows that the ART is effective enough to replenish CD4 count with in 6 months of the initiation of ART as suggested by the significant statistical value. ART is effective enough to improve the health status of the patients and quality of life because as high as $81.1 \%$ survival rate (10 deaths out of 53 ), high adherence and recovery rates were observed (Table 4). The basic principle of ART is that a set of combination of prescribed drugs blocks the replication of virus and hence there is less chance of increasing the viral load in the body resulting the replishment of CD4 cells there by prolonging the life of the patients. Recent studies of ART in resource poor setting have demonstrated the virological, immunological and survival benefits. A recently published report of a trial in Cameron of a fixed dose generic HAART regimen (which typically combines two nucleoside reverse transcriptase inhibitors with a protease inhibitors or a non- nucleoside reverse transcriptase inhibitors), in which $92 \%$ already had AIDS. After 24 weeks, $80 \%$ of patients had an undetectable viral load, and probability of surviving, $85 \%$. In practice, the success of ART depends on levels of adherence. Adherence is an important determent of survival (individual level). It is also essential for reducing the transmission of virus. ${ }^{7}$

In national level no specific studies were found on HIV patients with CD 4 count below 50 but several such studies with similar results were observed in other countries. A study conducted among HIV patients with CD4 count below 50 in Cambodia demonstrated that Tuberculosis was the most common AIDS-defining illness, with a prevalence of $43 \%$ followed by cryptosporidiosis (13\%), severe bacterial infections (12\%), cryptococcosis. ${ }^{8}$ Another similar study conducted among hospitalized HIV patients with CD4 count below 10 in Cambodia demonstrated Chronic diarrhea was the most frequent opportunistic illness $(41.2 \%)$, followed by tuberculosis (26\%) and cryptococcal meningitis (12.6\%). ${ }^{9} \mathrm{~A}$ TB/HIV epidemiological study carried out in HIV patients with CD4 count below 50 in Spain showed that Tuberculosis was the first AIDS-defining disease in $72 \%$ of the patients. ${ }^{10}$

\section{CONCLUSIONS}

It can be concluded that ART is effective enough in slowing the progression of HIV infection to AIDS and increasing the survival rate of patients with good performance. This study reflects the real situations of ART service in resource limited setting and help to promote the ART service to other parts of the country. On the basis of this study it can be recommended that HIV should diagnosed earlier so that ART can be started in appropriate time.

\section{ACKNOWLEDGEMIENT}

We would like to express our sincere thanks to Dr.Ganesh Bahadur Singh, Dr Hem Raj Pandey (SZH), Dr. Subash Sitaula of Family Health International (FHI), Dr. Santosh Basyal (FHI), Suresh puri (SZH), Prakash pandey (FHI), Sajana Shah (FHI), Lalmani Adhikari (FHI), Chitra Khanal, Deepa Bhattarai (SZH), Kalpana Bhatta (FHI) and other staffs of SZH and FHI who directly or indirectly involved in this study

\section{REFERENCES}

1. World Health organization, TB/HIV clinical manual, 2 nd ed. Geneva: WHO; 2004. p. 27-9.

2. Lyten L. Clinical HIV/AIDS care guidelines for resource poor setting. 2nd ed. Antwerp: Institute of Tropical medicine. 2006. p. 29-30.

3. Cheesebrough M District Laboratory practice in tropical countries, Vol. 2 Microbiology, Cambridge low price edition, 2001. p. 180-369.

4. Peutherer JF. Retrovirus. In: Greenwood D, Slack R, Peutherer JF. Medical Microbiology. 15th ed. Newyork: Churchill Livingstone; 2000. p. 518- 6.

5. National centre for AIDS and STI control (NCASC). Cumulative HIV/ AIDS situation of Nepal. Fact sheet updated on 12 April, 2008. p. 621-30.

6. Paudel BN, Khanal A, Paudel P, Sharma S, Singh GB. Retrospective study of HIV infection among migrants and

housewives in ART centre Dhangadi of far western Nepal PMJN 2008 Jun;8:52-6.

7. Daniel RH, Joshua AS Prevention and treatment of HIV in resource limited setting. Public Health reviews WHO. 2005 Feb; Vol. 83, p. 81-160.

8. Kong BN, Harwell JI, Suos P, Lynen L, Mohiuddin S, Reiner S, Pugatach D. Opportunistic infections and HIV clinical disease stage among patients presenting for care in Phnom Penh, Cambodia. South east Asian J Trop Med Public Health 2007 Jan; 38(1):62-8.

9. Senya C, Mehata A, Harwell JI, Pugatch D, Flanigan T, Mayer KH. Spectrum of opportunistic infections in hospitalized HIV-infected patients in Phnom Penh, Cambodia. J STD AIDS 2003 Jun;14(6):411-6.

10. Grau GI, Podzamczer D, Ramon J, Sanuy B, Alcaide F, Rufi G, Gudiol F Tuberculosis (TB) in HIV-infected patients with CD4 below 50/microL. Int Conf AIDS1998; 12: 287. 